\title{
PROPOSTA CURRICULAR DO ENSINO MÉDIO E A CONSTRUÇÃO DA AUTONOMIA DOS ALUNOS
}

Sandra Elias Takaki ${ }^{1}$, Helena Faria de Barros ${ }^{2}$, Anderson dos Santos Carvalho ${ }^{3}$, Maria Verônica Oliveira Tortola ${ }^{4}$

${ }^{1}$ Universidade do Oeste Paulista - UNOESTE, Curso de Pedagogia, Presidente Prudente, SP. ${ }^{2}$ Universidade do Oeste Paulista - UNOESTE, Mestrado em Educação, Presidente Prudente, SP. ${ }^{3}$ Universidade de São Paulo - USP, Programa de Pós Graduação em Ciências, Ribeirão Preto, SP. ${ }^{4}$ Professora Educação Básica, Especialista em Psicopedagogia. Email: sandtakaki@yahoo.com.br

\section{RESUMO}

O objetivo foi verificar como os conteúdos e o material didático do "Currículo de Língua Portuguesa" contribuem para a formação da autonomia do aluno no Ensino Médio. Metodologia: a pesquisa realizada foi um estudo de caso de abordagem qualitativa. Participaram do estudo 13 alunos de uma classe da $3^{a}$ série do Ensino Médio do período noturno, de uma escola pertencente ao município do Estado de São Paulo. O desenvolvimento da pesquisa ocorreu pela realização de duas situações de aprendizagem do "Currículo". Todo trabalho foi observado e registrado (ficha de observação e gravação áudio vídeo). Como resultado percebeu-se melhora no desenvolvimento dos alunos, no tocante à compreensão dos textos, além disso, houve evidências das competências de discernimento, de tomada de decisões e de relacionamento mais fácil com os pares.

Palavras - chave: Aluno. Autonomia. Conteúdo. Ensino Médio. Proposta Curricular.

\section{PROPOSED COURSE OF SECONDARY EDUCATION AND CONSTRUCTION OF AUTONOMY OF STUDENTS}

\begin{abstract}
This article aims to determine how the content and the teaching material of "Portuguese Language Curriculum" contribute to the formation of learner autonomy in high school. A qualitative approach to intervention characterizes the investigation. Were members / partners of the survey 13 students from a class of 3rd grade of high school the night period, a school belonging to the municipality of São Paulo. The research development occurred by the completion of two learning situations, as indicated in the "Curriculum". At the end of each situation, students drafted an essay as requested. All work was observed and recorded (audio plug observation and video recording). The interviews were organized with semi-structured questions always referring to the goals you want to achieve. As a result it was realized improvement in student development regarding the understanding of texts, in addition, there was evidence of the skills of discernment, decision making easier and relationship with peers.
\end{abstract}

Keywords: Student. Autonomy. Content. High School. Curriculum Proposal. 


\section{INTRODUÇÃO}

A autonomia, nesta pesquisa, é entendida do mesmo modo que a define Contreras (2002, p. 197), quando apresenta o profissionalismo docente. Segundo o autor, "a autonomia que se pretende na formação dos alunos não pode ser vista numa perspectiva individualista ou psicologista como se fosse uma capacidade que os indivíduos possuem". "A autonomia, assim como os valores morais, em geral, não é uma capacidade individual, não é um estado ou um atributo das pessoas, mas um exercício, uma qualidade de vida que usufruem nas relações sociais desenvolvidas".

De acordo com Contreras (2002), a autonomia das decisões profissionais e responsabilidade social é atuar em relação ao mais apropriado, é algo que requer processos reflexivos, os quais não podem manipular elementos que não estiverem assimilados por seus protagonistas, seja a partir de sua própria experiência seja pela proposição de uma tradição. Se a deliberação é sobre a forma de realizar o bem, nenhum professor poderá evitar agir em relação à sua própria concepção do que é o bem na educação, independentemente nas restrições ou das ordens às quais estejam submetidos.

Tradicionalmente, o conhecimento sempre foi visto como um conjunto de informações transmitidas pelos professores aos seus alunos. Nessa abordagem, os aprendizes assumiam o papel de ouvintes, cuja função maior era a memorização. Mesmo vislumbrando uma possível interação existente no silêncio dos estudantes, o professor não diagnosticava as dificuldades de aprendizagem manifestadas pelos alunos. O professor era visto como o detentor do saber, o responsável pela aprendizagem do aluno, somente ele era capaz de ensinar crianças e jovens.

De acordo com Freire (1983, p. 66), "ensinar no modelo tradicional, era transmitir conhecimentos, fazer com que a nova geração fosse capaz de reproduzir o que the foi ensinado." Os alunos não participavam das aulas, apenas ouviam e tinham que memorizar o conteúdo transmitido pelo professor; conteúdo que não era voltado para as necessidades da vida dos alunos, mas para a sistematização necessária à formação de pessoas capazes de se adaptarem à sociedade na qual estavam inseridos. A escola era vista como uma instituição única para todos, com os mesmos sentidos e objetivos, tendo como função garantir a todos o acesso ao conjunto de conhecimentos socialmente acumulados pela sociedade.

Acredita-se que somente por meio de uma relação de respeito mútuo, cooperação e tendo o aluno como sujeito construtor do seu conhecimento é que o professor poderá contribuir para a formação de indivíduos autônomos. Sob a ótica de conceber uma educação diferente, mais voltada ao ser humano e sua formação, surgiu o interesse da presente temática, visto que é 
inviável ensinar alunos dentro de um contexto tradicional, alterado por mudanças socioeconômicas e político-sociais.

Sendo assim o objetivo do estudo foi verificar como os conteúdos e o material didático do "Currículo de Língua Portuguesa" contribuem para a formação da autonomia do aluno no Ensino Médio.

\section{CONCEPÇÃO DE UMA EDUCAÇÃO CONTEXTUALIZADA NO SÉCULO XXI}

Percebe-se, atualmente, que a sociedade, as pessoas e os alunos mudaram. O contexto sócio-histórico é outro. A concepção fragmentada, estática, fixa, definida e previsível deu lugar à concepção de conhecimento inacabado, que está em constante construção. Não há mais conhecimento isolado, mas um o conhecimento dinâmico, interligado e contextualizado. É este o conhecimento que o aluno deve ter e adquirir.

Nessa perspectiva, cabe à escola muito mais do que a transmissão de saberes. É necessário um trabalho direcionado para o desenvolvimento do raciocínio e da autonomia dos estudantes, que estimule a reflexão, o diálogo, o discernimento, opções, tomada de decisões, lideranças e as ações pautadas em princípios de democracia e justiça. Para tanto, o trabalho da escola deve se articular às vivências dos estudantes, levando em conta seus contextos, suas experiências, seus conflitos e inquietações.

A concepção da educação contextualizada busca entender que as pessoas constroem seu conhecimento com base em seu contexto, no viver estabelecendo relações amplas. Ou seja, a construção dos saberes se efetiva na relação das pessoas com o mundo, com os outros e consigo mesmas. Para Reis (2005, p. 13):

A Educação Contextualizada e para a Convivência não pode ser entendida como um espaço de aprisionamento do saber, ou ainda na perspectiva de uma educação localista, mas como aquela que se constrói no cruzamento cultura-escola-sociedade. A contextualização neste sentido não pode ser entendida apenas como uma inversão de uma lógica curricular construtora e produtora de novas excludências.

Espera-se que o currículo seja o instrumento de aquisições dos saberes locais com os saberes globais, que seja visto como campo de transgressões, resistências, reflexões e possibilidade de criação.

Percebe-se que o Currículo do Estado de São Paulo fundamenta e sugere uma nova perspectiva para o ensino da Língua Portuguesa, que considera no trabalho do docente, o aprofundamento das questões que afetam a inclusão social, as teorias humanistas e cognitivistas, a 
descoberta de novas metodologias de ensino e a superação da barreira entre o que se ensina e o que realmente se aprende.

Portanto, no documento, o professor de Língua Portuguesa é visto como condutor do processo de ensino e de aprendizagem, auxiliando o educando na construção do seu saber e de sua autonomia, na compreensão e no uso de uma linguagem útil e necessária, tornando-o um sujeito capaz de realizar-se, satisfatoriamente, em suas relações pessoais e profissionais.

A relevância acadêmica desta pesquisa está nas dimensões trabalhadas: o sujeito na formação cognitiva, social e moral; na retomada das teorias relacionadas à temática, confrontando-as com as práticas de ensino; nos subsídios aos professores para que reflitam sobre a importância do seu papel na educação, ao libertar os alunos das convenções (obediência e comodismo) e ao estimular, assim, a ação do sujeito para a construção de conhecimentos, propiciando criticidade e reflexão.

Para a escola, é importante o tema proposto na medida em que tem como objetivo a ser desenvolvido junto aos alunos: partilhar em equipe, a temática da autonomia e da cooperação na aprendizagem escolar. É constante a preocupação e a contribuição com a formação de alunos cidadãos. Ao torná-los "sujeitos autônomos", possibilita-Ihes a construção de valores morais partindo de discussões sobre assuntos e ações que considerem a opinião do aluno, respeitando o grupo ao qual ele pertence.

De acordo com Contreras (2002, p.192), “a autonomia é vista como processo coletivo, dirigido à transformação das condições institucionais e sociais do ensino".

\section{A AUTONOMIA E SUA AUTOCONSTRUÇÃO}

A palavra autonomia é de origem grega e significa capacidade de autodeterminar-se, de autorrealizar-se. De "auto" (si mesmo) e "nomos" (leis), portanto, dirigir-se a si mesmo, isto é, estabelecer leis para si mesmo. Autonomia significa autoconstrução, autogoverno em relação ao grupo em que se está inserido.

De acordo com Piaget (1973, p. 48), “a autonomia não está relacionada com isolamento". Na verdade, Piaget (1973) entende que o florescer do pensamento autônomo e lógico operatório é paralelo ao surgimento da capacidade de estabelecer relações cooperativas, características do agir autônomo.

Para Piaget (1973, p. 49), "ser autônomo significa estar apto a cooperativamente, construir o sistema de regras morais e operatórias necessárias à manutenção de relações permeadas pelo respeito mútuo". E explica, ainda, que o desenvolvimento moral pode ser diferenciado em três momentos (anomia, heteronomia, autonomia). 
Podem-se perceber relações entre Piaget e Freire ao descreverem a evolução moral da pessoa humana e que esta evolução depende da formação, da educação.

Freire (1983) tem como pressuposto que o ser humano é histórico, circunstanciado em e por condições espaços-temporais e que quanto mais refletir de maneira crítica sobre a sua existência, mais poderá influenciar-se e ser (mais) livre.

$\mathrm{Na}$ integração com o contexto, desenvolve-se a reflexão, o comprometimento, construção de si mesmo e o ser sujeito. O ser humano é capaz de reconhecer que existem realidades que lhe são exteriores: tem capacidade de discernimento, relacionando-se com outros seres. E a capacidade de discernir leva a perceber a realidade que, por ser externa, é desafiadora - a resposta que se atribui a esse desafio transforma a realidade, sendo original. (FREIRE, 1983, p. 35).

Para Freire (2011, p. 58), considerar "a liberdade de outrem, à dignidade de cada um é um imperativo ético e não um favor que podemos ou não conceder uns aos outros". Diz o autor que ninguém é autônomo primeiro para depois decidir. Autonomia é construída em contextos de liberdade e de resistência, sem renúncia à individualidade, mas com desejo e empenho na formação de espaços solidários.

Nota-se que a educação para a autonomia deve ser conquistada, construída com base nas decisões, nas vivências, e na própria liberdade. Devendo, desse modo, a educação proporcionar contextos formativos que sejam adequados para que os alunos possam se fazer autônomos.

\section{METODOLOGIA}

\section{Delineamento e caracterização da amostra:}

Este estudo caracterizou-se como estudo de caso de abordagem qualitativa. A presente pesquisa foi desenvolvida em uma escola da Rede Pública de Educação do Estado de São Paulo, com 13 alunos da terceira série do Ensino Médio, com faixa etária de 17 anos, aproximadamente, do período noturno. O município pesquisado possui pouco mais de 5.567 mil habitantes, localizase na região Oeste do Estado de São Paulo.

Os critérios de inclusão para a realização da pesquisa foram: o aluno estar matriculado e aceitado a participar da pesquisa. Todos os sujeitos foram informados sobre a natureza, objetivos e procedimentos da pesquisa, tendo, em seguida, assinado um termo de consentimento livre e esclarecido, previamente aprovado pelo Comitê de Ética em Pesquisa (protocolo 1504) da Universidade do Oeste Paulista. 


\section{Procedimentos:}

Ao adotar tal abordagem metodológica, procurou-se realizar uma análise dos conteúdos e das atividades sugeridas pelo currículo de Língua Portuguesa em situações de aprendizagem e a possibilidade deles para a construção da autonomia dos alunos no ensino.

O desenvolvimento da pesquisa ocorreu pela realização de duas situações de aprendizagem do "Currículo". Todo trabalho foi observado e registrado (ficha de observação e gravação áudio vídeo). As entrevistas foram organizadas com questões abertas e fechadas referente aos objetivos que se pretendem alcançar.

O estudo foi considerando-se por meio de análise de conteúdo proposta por Bardin (1979); os estudos de Winter (1989) e a formação da autonomia pelo aluno; o Currículo de Língua Portuguesa no Ensino Médio (SÃO PAULO, 2008). Assim sendo, após opção metodológica realizou-se o procedimento de coleta dos dados da pesquisa.

\section{RESULTADOS E DISCUSSÃO}

Analisando os resultados da pesquisa, foi possível perceber que as Situações de Aprendizagem proposta no Currículo de Língua Portuguesa contribuíram no processo da autonomia dos alunos do Ensino Médio, uma vez que os mesmos apresentaram expectativas do seu projeto de vida, por meio da busca da sua realização profissional.

A autonomia se referiu, nesta pesquisa, às múltiplas capacidades do sujeito em representar-se tanto nos espaços públicos como nos espaços privados da vida cotidiana. A capacidade de potencializar atividades em diversas formas de trabalho; resolução de conflitos; fortalecimento em relação às suas próprias emoções, que o torna capaz de solidarizar-se com as emoções dos outros e, enfim, estar associado em suas ações, e um dos caminhos para a concretização dessas ações é trabalhar as competências, cabendo aos educadores esta função.

Se a escolha não é outra senão "decidir como ser e como agir" (GIDDENS, 1997, p. 94), o como "ser e agir" num contexto globalizado diz respeito à escolha de comportamentos, maneiras de participação nos espaços públicos, atitudes no espaço da produção e do consumo. Esta escolha, entretanto, não é mais dirigida por regras fixas, mas sim pela flexibilidade, o que leva a destacar que a ação envolvida nesse processo precisa ser consciente - peça essencial para a autonomia.

A escola, portanto, nesta pesquisa representada no discurso dos adolescentes, é considerada como importante e fundamental, pois Ihes possibilita a aquisição do conhecimento o saber, o pensar - e oferece capacidades que oportunizam a conquista de trabalho no mercado. 


\section{CONCLUSÃO}

A pesquisa desenvolvida evidenciou que os conteúdos e o material didático utilizado nas situações de aprendizagem contribuíram para a construção da autonomia dos alunos da 3a série do Ensino Médio.

Nota-se que, que o material potencializa as oportunidades para os alunos mobilizarem seus conhecimentos, atitudes e capacidades de pensamento crítico ligado ao currículo de Língua Portuguesa.

\section{REFERÊNCIAS}

BRASIL. Parâmetros Curriculares Nacionais: Ensino Médio. / Ministério da Educação, Secretaria de Educação Média e Tecnologia. - MEC; SEMTEC, 2002.

CONTRERAS, J. A Autonomia de Professores. São Paulo: Cortez, 2002.

FREIRE, P. Pedagogia do oprimido. 12 ed. Rio de Janeiro: Paz e Terra, 1983.

. Pedagogia da Autonomia. Saberes Necessários à Prática Educativa. São Paulo: Paz e Terra, 2000.

FREIRE, P. Pedagogia da Autonomia: Saberes Necessários à Prática Educativa. São Paulo: Paz e Terra, 2011.

GIDDENS, A. Modernização Reflexiva: Política, Tradição e História na Ordem Social Moderna. São Paulo: UNESP, 1997.

MOREIRA, A. F. B.; SILVA, T. T. (Orgs.). Currículo, cultura e sociedade. 2. ed. São Paulo: Cortez, 1997.

MORENO, M. Temas transversais: um ensino voltado para o futuro. São Paulo: Ática, 1997.

PIAGET, J. A psicologia da Enquête. São Paulo: Difusão Européia do Livro, 1973.

REIS, E. S. R. Projeto de Doutoramento apresentado à Universidade Federal da Bahia. Salvador: UFBA, 2005.

SÃO PAULO (Estado) Secretaria da Educação. Proposta Curricular do Estado de São Paulo para o Ensino Fundamental Ciclo II e Ensino Médio: documentos de apresentação. São Paulo: SEE, 2008.

Currículo do Estado de São Paulo: Linguagens, Códigos e suas tecnologias - Ensino Fundamental Ciclo II e Ensino Médio Secretaria de Educação; Coordenação geral, Maria Inês Fini; coordenação de área, Alice Vieira. - São Paulo: SEE, 2010.

SIQUEIRA, E. M. Luzes e sombras: modernidade e educação pública em Mato Grosso (1870-1889). Cuiabá: INEP/COMPED/EdUFMT. 2000. 